\title{
Design in the Anthropocene: Restoring the Los Angeles Ballona Wetlands Ecological Reserve
}

\author{
NICOLE LAMBROU \\ Academy of Art University
}

\begin{abstract}
The language of emergency that surrounds climate change is the foundation for its solution: the management and control of climate through the active management of nature. How we define and understand nature frames how we conceive of interventions. The actors, and their message, selected to formulate and implement these interventions are intimately tied to a specific concept of nature.
\end{abstract}

Restoration ecology aims to restore a landscape to a previous ecological function either in part or in whole. In recent years it has become standard practice to invoke this phrase in urban settings, an effort by cities to situate themselves at the forefront of urban ecological planning. This paper looks at one of those instances, the Ballona Wetlands in Los Angeles, and the contestations around its restoration, as a rehearsal for how we address urban natures.

The contestations surrounding the creation and management of urban natures is not limited to coastal wetlands, but reverberate across the city landscape. Contestations surrounding restoration projects tend to reinforce the false distinction between the social and the natural, and belie contradictions we confront in joining the supposed natural to the alleged artificial. An assemblage of viewpoints on what constitutes a proper wetland, perspectives that partly overlap and quickly deviate from each other, reveals the contestation of ideas surrounding urban nature. These perspectives are further embedded in competing ideas of entitlement and ethics: who is the public, what is the space of public land, and what rights does one have over the other?

\section{A NATURAL EXPERIMENT}

The question of nature is, in part, a question of power relations. Restoration ecology, the act of restoring land to its prior ecological function, is part of our relentless attempt to manage the unpredictability of climate change. In the case of the Ballona Wetlands in Los Angeles, rather than confronting a seeming swamp interlaced with burrowing voles and trash, it is far more straightforward to replace it with a constructed lagoon brimming with the vitality of fish, plants, and birds. If those species are endangered, all the better to assuage the work we've done that led to the degradation in the first place.

Wetland definitions vary worldwide. In the the United States the U.S. Army Corps of Engineers and the U.S. Environmental Protection Agency together define wetlands as "those areas that are inundated or saturated by surface or ground water at a frequency and duration sufficient to support, and that under normal circumstances do support, a prevalence of vegetation typically adapted for life in saturated soil conditions. Wetlands generally include swamps, marshes, bogs, and similar areas." A wetland is defined, quite broadly, as an area where the water table is at or near that of the ground, and where that water level persists long enough to sustain aquatic plants. Typically situated at the interface of land and water, wetlands act as zones that reconcile the transition from fully terrestrial to fully aquatic ecosystems. The periodic inundation of water spurs anaerobic processes to which certain aquatic plants adapt.

The land that now constitutes the Ballona Wetlands was once a smaller part of a 2,000-acre area made up of sand dunes, mud flats, lagoon and marsh. The Los Angeles River once drained through Ballona into the ocean, before a series of earthquakes redirected its flow south, leaving Ballona Creek as the connector between the coast and the watershed further inland. ${ }^{2}$ The Sa'anga people of Tongva depended on this land for agriculture production and fishing before Spanish settlers colonized coastal land in the late 1700's, at which time they enslaved the Sa'anga, moved them to Pasadena and named them Gabrielenos.

Developer Henry P. Barbour purchased about 1,000 acres of the lagoon in the early 1900s and set up a boardwalk, pavilion, restaurant, dance floor and bowling alley, eventually renaming the development Playa del Rey, while the LA Pacific Railway Company followed up with the construction of a hotel. This surge in development attracted the interest of businessman Abbot Kinney, who then drained the remaining swamps in order to build canals with arched bridges over them, importing gondolas and gondoliers from Italy and renaming the creation 'Venice of America.' ${ }^{3}$

Oil mining in the Ballona wetlands ensued, with the number of active oil wells reaching 325 by the 1930s. During that same time the U.S. Army Corps of Engineers channelized the Ballona Creek to mitigate the damages caused by flooding. It wasn't until World War II that the oil in this area was depleted and the Southern California Gas Company started storing natural gas in the caverns under the ground and which were no longer used for oil. Howard Hughes purchased what is now considered Playa del Rey along with the Ballona Wetlands in the 1940s. On this land Hughes built aircrafts and electronics for the U.S. military during the Cold War, along with Marina del Rey which destroyed half of the remaining wetland area. 
With increasing awareness of environmental degradation through industrial land use, coastal protection entered environmental and policy-making circles and the California Coastal Commission was formed in the early 1970s. A 1990 lawsuit settlement called for the preservation of about 300 federally-designated wetland acres throughout the Ballona Wetlands. When several movie studios announced their plans to move their production to Playa Vista the 1990s environmental group Wetland Actions Network helped convince the Coastal Conservancy to buy an additional 190 acres, and in 2003 California purchased Ballona through the Trust for Public Land, at which point the California Department of Fish and Wildlife designated the assembled wetland acreage an ecological preserve.

The wetland area is a haven for homeless people as well as for feral cats, trash, and over 3 million cubic yards of sediment deposited in this area as the result of the construction of Marina del Rey. To help set a framework within which restoration efforts can be conceived, the independent nonprofit Santa Monica Bay Restoration Foundation commissioned a study in 2012 to determine how the Ballona Wetlands functioned between 1850 and 1890, as if environmental ethics are somehow tied up with recreating particular moments in history.

In considering Los Angeles in particular, Dana Cuff writes that "a contentious and local activism responds to the convulsions in its vicinity. The geography of planning, then, is as convulsive as the developments that spark it. In concert with the architecture of a sporadic urbanism, itself politically charged, this constructs a new way of looking at city form." 4 The Playa Vista development and resulting state of the Ballona Wetlands is exactly the result of such a process. The only remedy against a growing number of interest groups, each equipped with different environmental laws to bolster their arguments, seems to be evermore participatory design. Repeated calls for including as many stakeholders as possible in the process of negotiating urban natures, whether restoring habitat or building new development, reverberate across 'best practices' and 'lessons learned' documents.

\section{CONTESTATIONS}

Coined in the 1980s, the term 'restoration ecology' defines a practice by which humans could restore degraded environments through their active transformation and management. What form that restoration should take, how extensive it should be, and what condition is the right one to restore to are all contested grounds, both in ethical and biophysical terms.

Even murkier territory is determining whether natural disasters, such as the earthquake that led to the LA River being diverted away from the wetlands in the early 1800 s, or others that may be expedited and shaped by human activity, should be taken as the penultimate point of restoration. Questions of whether the Ballona Wetlands should be returned to a functioning freshwater or a functioning saltwater marsh again rest on ones definition of a natural or human disruption, a question fundamentally rooted in ethics, as if those two - natural and human - exist in separate realms. All such discussions conceal the fact that urban ecology is a highly constructed endeavor, actively managed and configured.

The local Sierra Club, a number of politicians, and some local ecologists believe that a gentle intervention in Ballona is required, as anything more will impact the existing ecosystem to a dangerous degree, killing off animal and plant life that the wetlands now support. The Los Angeles Audubon, headed by Travis Longcore, cites Malibu Lagoon as proxy for the unintended consequences of large-scale ecological restoration projects. ${ }^{5}$ Malibu Lagoon succeeded in opening up the lagoon for more water to circulate through, filtering it and rendering it healthier for the surrounding ecosystem, but in so doing it obliterated the habitat of the south coast marsh vole, a state species of some concern, which also exist in the Ballona wetlands.

A number of environmental groups call for a careful historical reading of each wetland area's unique landscape conditions to counter the state-led generic and heavy-handed approach of permanently opening up what were once ephemeral inlets, breached only intermittently through winter storms, and replacing these with fully tidal lagoons in the process. Changing the lagoon landscape in such a drastic and permanent fashion, they argue, dispenses with the established seasonal habitats that allow migratory species to move through the wetlands. This method of ecological restoration is seen throughout the coast of California, they claim, acts that have increased the amount of open ocean water that directly meets the California coast many times over. While restoration is necessary, in other words, we should study nature's ecology and mimic it in our restoration efforts rather than directing efforts on replacing brown sludgy water with a clear blue one.

The Coastal Conservancy, along with the California Department of Fish and Wildlife, local nonprofits and the Science Advisory Committee see the Ballona Wetlands as dysfunctional, reinforced by the low rating it received by the EPA, a measure of its deteriorating state, and in need of active management. Their proposals involve substantial movement of earth by removing old construction waste, redesigning the straight creek into a meandering one that can support tidal movements, and removing the levees that cut through the wetlands as they approach the ocean. On this side of the fence the Santa Monica Bay Restoration Commission doesn't disagree with the historical assessment of the wetlands but stresses the importance of removing the levees in order to allow the wetlands to receive water again - even if it's ocean 
water. Saltwater marsh can serve the wetland restoration objectives by turning this area into a functioning habitat that can be sustained over time.

Yet other environmental groups, community stakeholders, and local Sierra Club leaders, point to the importance of not disturbing the existing land at all. From this point of view, framing the problem as one of environmental degradation diverts attention from what is currently working in the wetlands, the species that already depend on this land for survival in the present moment, and towards solutions that are circumscribed within scientific literature. For them, the use of science as guidance for how to deal with environmental degradation - by removing the toxicity and moving earth around so that the optimal water flow is achieved - is exactly the problem that degraded the environment in the first place, namely the human hand.

All of these perspectives share the same understanding of the essential characteristics of wetlands. They agree that wetlands are important actors in urban ecology in that they filter stormwater, provide habitat for aquatic species, including birds and plants, and even act as a buffer for inland development against storms. The fact that over 90 percent of Southern California's original 49,000-acre coastal wetland area has been lost is often cited by all groups involved in the Ballona Wetlands discussions. In a sense, though, these competing ideas on restoration are, when implemented, a test of how well we understand nature. Each group vehemently opposes the other, citing ecological evidence that their approach to altering the landscape is the most effective in meeting common ecological goals.

When science, a reflection of our understanding of nature, offers as many solutions as there are interpretations of how nature should function best, resolution dissipates. "But how," Jasanoff asks when debating the role of science in decoupling meaning from knowledge, "can anyone speak meaningfully, let alone act with confidence, with respect to a nature that is hybrid, fluid, contingent and endlessly deconstructible?"6 If we are to understand nature as a process rather than a fixed condition, what does a meaningful and ethical action look like?

The limits to shared interpretations are stark. The perspectives outlined here are the predominant ones surrounding this particular environmental restoration project, and they diverge in exceptional ways when it comes to the question of urban natures precisely because of competing definitions of nature. On the one hand, the ecosystem is seen as too sensitive to touch, a fragile ecology in need of protection against the force of human development that brought it to this state of degradation. On the other hand, nature is not only resilient, able to be restored to a healthier and more functional and robust ecosystem, but human participation is a necessary force for that restoration to take place. The wetlands need not be preserved, but should be constructed. And then re-constructed.

Those ecologists on this latter part of the debate see nature as requiring human intervention. They further embrace just how much work and labor is involved in managing ecological functions - the active construction of nature:

"Sediment contamination (chemical and biological), quality, and quantity are critical variables to consider prior to and during the construction process....On-site managers who understand the principles of restoration and construction logistics need to constantly communicate with construction crews in order to provide the strongest environmental protection."7

What these different realities reveal is that there is multiplicity in our interface with nature. That interface is a stage onto which power relations, politics, and culture stake their claims. As Rademacher observes in her investigation of the the river restoration in Kathmandu, a multiplicity of mindsets not only obscures fully cohesive understandings, but "compels us to attend to the stakes of the competition over what urban ecology means to differently positioned actors. In this case, the stakes were no less than entitlement to direct the social and environmental future of Nepal's capital city - its form, its 'natural' spaces, and the distribution of environmental and political power among its inhabitants." 8

This is not to say that the wetlands should not be restored, or that scientific knowledge, however incomplete in communicating the fullness of an environment, is flawed. Rather, the discussion of the Ballona Wetlands restoration, and all the contestations around this land, forces us into a conversation with nature that is at once intensely intimate and an object of inquiry. How do we reflect on that which we essentially are and are not? This is environmental ethics.

These multiple understandings of nature inform who should be involved in wetland restoration discussions and privilege certain solutions over others. Urban ecologies rest on definitions of nature that are slippery, yet compose frameworks within which particular sets of ideas are included and others excluded. Rademacher urges us to pay attention to how conflicting ideologies interface: "What is important to notice are the ways that each framing established in competing ways its legitimacy, its urgency, and its knowledge priorities." ${ }^{9}$ Socioenvironmental parameters demarcate conceptual and spatial territories, and are as engrained in political decision-making processes as they are in our shared narratives. These narratives seduce because they obscure complexity, and they persist in propping up the myth of the sustainable city. 


\section{RESILIENCE}

Ecologists posit that one of the major threats to wetlands is sea level rise, spurred on by climate change induced by humans. ${ }^{10}$ They propose that the restoration of wetlands be mindful of the manner in which climate change shifts environmental forces, such that restoration efforts should be directed towards constructing habitats that can survive anticipated climate-change disruptions in the future. In this sense they recognize that wetlands cannot be thought of as a restoration project in the face of climate change:

"The trajectory of climate change is moving wetlands away from the 'natural' or 'historical' wetlands of days gone by. Developing goals for restoration that focus on function will provide for the most resilient and sustainable habitats in the future. Determining which sites have the greatest ability to transgress with sea level rise and sustain necessary habitats is important, as these may provide the greatest protection of biodiversity across the region." ${ }_{11}$

These are the ecologists who argue that a resilient habitat in the case of Ballona is one that promotes saltwater rather than a return to a freshwater marsh, despite the fact that this would mean not reverting to the ecology's historic function.

It's important to clarify, at this point, how different notions of resilience frame the perceived problems of a landscape that then solicit certain responses. In the concept panarchy, ecologists Gunderson and Holling propose that both fast and slow dynamics examined over different scales and different relationships, from interactions to interdependencies, all contribute to an ecosystem's resilience. ${ }^{12}$ In the first definition that Holling puts forth resilience is defined as the ability of a system to return to the state it was in prior to a disturbance. The sets of relationships and characteristics that form the essence of that system, in other words, are persistent and able to absorb changes imposed from the outside. The system in question is able to self-manage its way back to equilibrium.

Holling later recognized that this definition is limited in that it only looked at a specific process, that of predation, within a framework of limited functions and responses. It wasn't until he accounted for a larger set of actors in a system, combined with extending the analysis to encompass multiple spaces and time scales, that the idea of an ecosystem began to emerge. ${ }^{13}$ In an ecosystem, resilience involves non-linear processes that do not reach equilibrium. After absorbing external shocks, whether those are long in the making or short-term ones, hierarchies of relationships shift to absorb the changes caused by the disruption, resulting in a new set of relationships where a different set of actors in the regime come into focus. This process takes place across many scales of space and time, and so the regime is always in flux.
The first definition of resilience described above is referred to as engineering resilience, relying on linear, stable, and self-managed equilibrium, while the second one is ecological resilience, which focuses on adaptation and self-reflection. A key aspect of both is that the system learns from a disturbance and recombines itself, forming new relations and new movements, and perhaps even incorporates different scales and spaces. But if we understand ecology, the landscape, the processes that govern the planet as entirely implicated in human agency, and vice versa, what does it mean to then say that a system recombines itself? This is a fundamentally ethical question.

Automatic and self-regulating processes do not exist. In the Ballona restoration project, if not in all restoration cases, people are not at the service of a greater process that will rearrange itself and reset the system on their behalf or in spite of their presence. These definitions of resilience do not capture exactly how much effort, management, and intervention is needed in order to maintain the essential function of an ecology, however in flux that ecology may be. Sustaining ourselves and our landscapes is as willful and manipulative, and as intertwined with technology, as the very acts of resource extraction that engender environmental disruptions.

\section{DOMESTICITY}

Restoration does not change our relationship to nature, a relationship that is arguably the source of our surrounding and pervasive climate change. Instead, it sells itself as a call for humans to re-establish an aesthetic connection to nature as opposed to an ethical one. Rather than argue for that reconnection to take place through concerted efforts to break through carbon lock-in and usurp regulations and behavior that continue to promote the use of fossil fuels, for example, restoration ecology allocates significant funds towards engendering a healthy ecology in a discrete urban location. We can walk on elevated pathways that meander through this constructed piece of nature where wetland life blooms, a hypernature of sorts, without ever touching it and then return to the safety of our antiseptic homes. The image of the ethical, sustainable city remains decisive in the global urban spotlight.

To move beyond the image, in his first of four theses historian Dipesh Chakrabarty posits that climate change is proof that human history has collapsed onto natural history, the two indiscernible from each other. Where environmental historians see people as biological agents first and foremost, climate scientists see them as geological agents, conflating the history of the human species with the geological history of the planet. ${ }^{14}$ Timothy Morton brings the same analogy to the present moment:

"For some time we may have thought that the U-bend in the toilet was a convenient curvature of ontological space that took whatever we flush down into a totally different 
dimension called Away, leaving things clean over here. Now we know better: instead of the mythical land Away, we know the waste goes to the Pacific Ocean or the wastewater treatment facility." ${ }^{15}$

The space that once separated Away and Here is gone. Metabolic flows, exurban development, planetary urbanism, and urbanrural dependencies all continue to reinforce this idea, albeit in different ways.

Deliberating on ecology within this framework forces us to relinquish the central role we've assumed in measuring and ordering nature, in that it reveals the chasm between our use of the physical materials around us and the cozy images of nature we conjure up when we think of ecological restoration. Within this framework, where we are aware that everything is the product of our interaction with it, and where we, in turn, are a product of that interaction, what is the meaning of restoration ecology? If Chakrabarty is right and a history devoid of humans has lost its significance, what, precisely, are we restoring and what are we restoring it to? Lawrence Vale offers this:

"The will to rebuild is rooted in efforts to control the recovery storyline in ways that benefit dominant groups, to rely on symbolic acts of rebuilding as a means to signal resolve, and to support a highly politicized redevelopment agenda. Humandominated social systems are different from ecological systems because of these three things: they rely on the power of human stories, depend on the human capacity to invent powerful symbols to guide action, and rise or fall in accordance with the human ability to exercise political power." ${ }_{16}$

Urban natures emphatically meet all these criteria, passing from the hands of owner to interest group and back again, all the while assuming fragile or robust definitions of nature depending on who is holding the spotlight. The Ballona Wetlands is such an urban nature, a domesticated human-dominated social system.

The wild is no more an imaginary now than it was ten thousand years ago when human first planted wheat and barley. If nature is synonymous with 'untouched-by-humans,' and if there is no history outside of human history, then there is no such thing as nature. It is a construct, profoundly implicated with the human species even as it persists as an object of reflection. As nature becomes urbanized, that which is urban is more natural:

"If the Neolithic Revolution gave birth to 'the city', then the industrial revolution gave birth to 'the urban', and if the first altered the natural environment, then the second abolished the concept of nature altogether. 'Urban-nature' is the condition of living on industrial Earth: a 'world' of domesticated nature and wild urbanization." ${ }^{17}$

Urban natures extend to landscape transformations at a scale that is reminiscent of Modern planning: Rebuild by Design in
New York, the LA River Revitalization Plan, rebuilding the Gulf Coast Region, the Garuda Dam project in Indonesia, Resilient by Design in the San Francisco Bay Area, and a series of other restoration projects too numerous to list here, are all reactions to the emergency of climate change. Competing understandings of nature, supported by adaptable scientific claims for what constitutes an ecology, are brought to bear on environmental ethics.

As urban regions continue to declare their intentions to pioneer the next chapter in the making of an environmentally ethical city, spatial and geologic trajectories point elsewhere. Putting aside the question of what, precisely, constitutes the urban, an important but contestable point, the fact that urban regions hold concentrations of power, wealth, and energy consumption is indisputable. This is the case even in the face of an increasing body of literature that seeks to connect urban flows to the larger regions that those flows stem from, end up in, and have a tangible effect on. Any definition of environmental ethics must therefore be understood through the politics that shape urban-natures, in turn rooted in our understanding of nature. And nature is the Anthropocene embodied.

\section{ENDNOTES}

1 U.S. Army Corps of Engineers. "Recognizing Wetlands: An Informational Pamphlet." Retrived from www.usace.army.mil/Portals/2/docs/civilworks/ regulatory/techbio/rw_bro.pdf on August 17, 2017.

2 Alma Gottlieb, The Restless Anthropologist: New Fieldsites, New Visions (Chicago: The University of Chicago Press, 2012).

3 John McKinney, A Walk Along Land's End:Discovering California's Unknown Coast (New York: Harper Collins, 1995).

4 Dana Cuff, The Provisional City: Los Angeles Stories of Architecture and Urbanism (Cambridge: The MIT Press, 2000): 59.

5 Judith Lewis Mernit, "The Los Angeles wetland wars" High Country News, Retrived from http://www.hcn.org/issues/47.8/the-los-angeles-wetland-wars on July 2016.

6 Sheila Jasanoff, "A New Climate for Society," Theory, Culture \& Society, Vol. 27 (2010): 245.

7 Fejtek, S., Gold, M., MacDonald, G.M., Jacobs, D., Ambrose, R., "Best Practices for Southern California Coastal Wetland Restoration and Management in the Face of Climate Change," Retrived from http://escholarship.org/ uc/item/3zx2j5br (Los Angeles: UCLA Institute of the Environment and Sustainability, 2014): 4 .

8 Anne Rademacher, Reigning the River: Urban Ecologies and Political Transformation in Kathmandu (Durham, NC: Duke University Press, 2011): 58.

9 Ibid, 89

10 Fejtek, et.al., "Best Practices for Southern California Coastal Wetland Restoration and Management in the Face of Climate Change," 1.

11 Ibid, 2.

12 Carl Folke, "Resilience: The Emergence of a Perspective for Social-ecological Systems Analyses," Global Environmental Change Vol. 16, (2006): 257.

13 C.S. Holling, "Engineering Resilience Versus Ecological Resilience," Engineering Within Ecological Constraints, Schulze, P. ed., (Washington, DC: National Academy Press: 1996): 31-44.

14 Dipesh Chakrabarty, "The Climate of History: Four Theses," Critical Inquiry Vol. 35 (2009): 197-222.

15 Timothy Morton, Hyperobjects, Philosophy and Ecology after the End of the World (Minneapolis: University of Minnesota Press, 2013): 31.

16 Lawrence Vale, "Resilient Cities: Clarifying Concept or Catch-All Cliche?" The City Reader, 6th Edition, LeGates, R. and Stout, F. eds., (2015): 23.

17 Harry Gugger and Barbara Macaes Costa "Urban-Nature: The Ecology of Planetary Artifice," San Rocco: Ecology, Vol. 10 (Venice: San Rocco, 2014): 40. 